\title{
Sobre ciertos lugares comunes del pensamiento geográfico contemporáneo. El interés de la aportación del filósofo Jeff Malpas al pensamiento acerca del lugar
}

\author{
Paloma Puente Lozano \\ Universidad Carlos III de Madrid. Instituto de Historiografía Julio Caro Baroja \\ ppuente@hum.uc3m.es
}

\section{Resumen}

El artículo tiene como objetivo introducir a los geógrafos del ámbito hispano en la obra del filósofo australiano Jeff Malpas, cuya reflexión sobre el concepto de lugar pone de relieve algunas de las principales limitaciones y problemas del modo en que se ha producido la teorización de ciertos conceptos geográficos en el marco del pensamiento geográfico crítico anglosajón. El artículo parte de un balance general, con vocación ciertamente polémica, de las retóricas y los lugares comunes de esa forma de crítica de pensamiento geográfico, para, a continuación, defender la relevancia de la obra de Jeff Malpas en el contexto de dichos debates recientes. Justificamos su aportación filosófica a través de la consideración de dos aspectos de su obra: su reflexión ontológica sobre el lugar y su crítica al predominio de modos constructivistas de razonamiento en la geografía que, precisamente, debilitan cualquier reflexión sobre la noción de lugar que pretenda hacer justicia a la estructura topológica de la experiencia humana. Ambos aspectos, que aquí presentamos poniéndolos en diálogo con las posturas dominantes en el pensamiento geográfico anglosajón, permiten entender y discutir el sentido profundo de la propuesta de Malpas de "pensamiento topográfico».

Palabras clave: pensamiento geográfico; geografía anglosajona crítica; lugar; constructivismo; Jeff Malpas.

Resum. Sobre certs llocs comuns del pensament geogràfic contemporani: L'interès de l'aportació del filòsof Jeff Malpas al pensament sobre el lloc

L'article té com a objectiu introduir els geògrafs de l'àmbit hispà en l'obra del filòsof australià Jeff Malpas, la reflexió del qual sobre el concepte de lloc posa de relleu algunes de les limitacions i dels problemes principals de la manera com s'ha produït la teorització de certs conceptes geogràfics en el marc del pensament geogràfic crític anglosaxó. L'article parteix 
d'una avaluació general, amb vocació certament polèmica, de les retòriques i dels llocs comuns d'aquesta forma de crítica de pensament geogràfic, per, a continuació, defensar la rellevància de l'obra de Malpas dins del context dels debats recents. Justifiquem l'aportació filosòfica de Malpas a través de la consideració de dos aspectes de la seva obra: la reflexió ontològica sobre el lloc, i la crítica al predomini de maneres constructivistes de raonament en la geografia, que, precisament, debiliten qualsevol reflexió sobre la noció de lloc que pretengui fer justícia a l'estructura topològica de l'experiència humana. Tots dos aspectes, que aquí presentem posant-los en diàleg amb les postures dominants en el pensament geogràfic anglosaxó, permeten entendre i discutir el sentit profund de la proposta de Malpas de "pensament topogràfic».

Paraules clau: pensament geogràfic, geografia anglosaxona crítica, lloc, constructivisme, Jeff Malpas.

Résumé. Des lieux communs dans la pensée géographique contemporaine. L'intérêt de l'apport du philosophe Jeff Malpas à la pensée sur le lieu

Cet article cherche à introduire les géographes hispanophones dans la pensée du philosophe Australien Jeff Malpas, dont la réflexion sur le concept du lieu reste d'intérêt face aux problèmes que les théorisations développées par les géographes critiques anglo-Saxons présentent. L'article commence par dresser le bilan, d'une façon ouvertement polémique, des rhétoriques et clichés d'une certaine façon de pratiquer la critique dans la pensée géographique anglo-saxonne. C'est par rapport à cette situation que l'apport de Malpas à la géographie prend davantage son sens. Deux aspects de son travail sont donc abordés ici, notamment, sa réflexion ontologique sur le concept de lieu, et sa critique des modes d'argumentation constructivistes qui prédominent parmi les géographes critiques angloSaxons, étant donné que ceux-ci empêchent sérieusement une réflexion sur le lieu, qui prenne en considération la structure topologique de l'expérience humaine. La considération de ces deux questions, dans le cadre de leur confrontation avec les théories géographiques critiques, aide à mieux comprendre le vrai sens de l'approche de Malpas, ainsi nommée "pensée topographique».

Mots-clés: pensée géographique; géographie critique anglo-saxonne; lieu; constructivisme; Jeff Malpas.

Abstract. Revisiting certain commonplaces of contemporary geographic thought: The interest of Jeff Malpas' thinking about place

The paper aims to introduce geographers within the Spanish-speaking community to the work of Australian philosopher Jeff Malpas, whose reflection about place sheds light on the several pitfalls of existing theorizations about geographic concepts developed within the frame of Anglophone critical geographic thought. The paper takes as its starting point a controversial assessment about the most commonly used spatial rhetoric and vocabularies within critical geographic thinking. It then goes on to argue the importance of Malpas' thought by taking into account two related aspects of his work: his ontological treatment of place, and his criticism about mainstream constructivist modes of argumentation in geography, since those ultimately hinder any serious reflection trying to give place their due, that is, one based on the acknowledgment of the topological structure of human experience. Both issues allow for a discussion of mainstream stances within critical geographic thought and to what extent Malpas' proposal of "topographic thinking" makes a difference.

Keywords: geographic thinking; Anglo-Saxon critical geography; place; constructivism; Jeff Malpas. 


\section{Sumario}

1. Introducción. La necesaria tarea de cuestionar y descreer de las retóricas espaciales contemporáneas

2. El lugar y la estructura topológica de la experiencia

3. El constructivismo en la cultura epistémica contemporánea y el argumento contra el lugar
4. Conclusiones. Pensamiento topográfico y pensamiento geográfico

Agradecimientos

Referencias bibliográficas

\section{Introducción. La necesaria tarea de cuestionar y descreer de las retóricas espaciales contemporáneas}

La historia reciente de las corrientes y de los debates en la geografía anglosajona contemporánea, especialmente en sus variantes críticas, es de sobra conocida en el ámbito hispano y ha sido contada y analizada en numerosas ocasiones por geógrafos (cfr. García Ramón, 1985; Capel, 1981, 1987; Ortega Cantero, 1987; Ortega Valcárcel, 2002; Delgado Macheca, 2003; Lindón y Hiernaux, 2007, 2011). Esta historia disciplinaria se entrecruza, y a menudo se confunde de una manera muy particular, con una historia más amplia, la del pensamiento contemporáneo y la de sus profundas transformaciones epistemológicas, ya que los diversos y persistentes esfuerzos de muchos geógrafos anglosajones desde la década de 1970 por anclar firmemente la disciplina en el marco de las preocupaciones y de las tareas críticas de la teoría y de las ciencias sociales, ha generado una dependencia (gozosa, por cierto, para no pocos) respecto de esos esquemas y problemas epistemológicos.

Por supuesto, pretender que la geografía, o cualquier disciplina, esté al margen de los avatares epistemológicos y metodológicos que atraviesan las ciencias de su tiempo es, evidentemente, una ingenuidad tan falta de sentido como lo es pretender hacer historia de cualquier disciplina sin atender a la profunda trabazón del conocimiento en los contextos históricos e institucionales en que éste se produce y se difunde. Sin embargo, hay una serie de peculiaridades en la manera en que esta relación se ha dado en la geografía pospositivista anglosajona, que todavía hoy no ha recibido, en las historias disciplinarias, un análisis epistemológico pormenorizado que alcance a mostrar los efectos y las implicaciones profundas de dicha trayectoria histórica y de la situación presente en que ésta ha desembocado.

La larga y sinuosa salida del esencialismo geográfico ha llevado a los practicantes de la disciplina a transitar los más variados caminos en su tenaz esfuerzo por replantear de raíz los fundamentos sobre los que ha de pensarse y definirse la espacialidad ${ }^{1}$. Que la geografía crítica anglosajona se ha erigido como el

1. Cfr. Staddon (2009: 371) para un rápido balance sobre la concatenación y, en determinados momentos, el solapamiento de estrategias estructuralistas, humanísticas y posestructuralistas (todas ellas prolíficamente practicadas, en especial, las últimas referidas, en su más diversas, 
máximo exponente de dichos esfuerzos parece un hecho innegable; sin embargo, no es menos cierto que tal coyuntura está estrechamente relacionada con la proverbial capacidad que esta geografía ha mostrado para domesticar las más diversas fórmulas y vocabularios de la teoría contemporánea, hasta el punto de que parece cada vez más difícil encontrar, por esos pagos, un análisis geográfico que, teniéndose por debidamente "crítico", no salpimiente de manera ágil sus textos con prolijas alusiones a éste o aquel teórico de moda, fuente inagotable, y sin duda fecundísima, de inspiración geográfica. El esclarecimiento de cuál es la naturaleza de dicha relación entre la refundación pospositivista de la disciplina y tales estrategias retóricas es una tarea urgente que resta aún por hacer, y convendría llevarla a cabo, por cierto, sin los pudorosos reparos que, a menudo, son de rigor cuando se habla de pensamiento "crítico», pues, si de crítica se trata, la tarea comienza por uno mismo.

En este sentido, el análisis de cómo la hegemonía anglosajona ha marcado la pauta y el devenir críticos de la disciplina en estas últimas décadas ha de poner de relieve, especialmente, la naturaleza de los argumentos y de los razonamientos que están detrás de las retóricas espaciales críticas al uso, lo cual ayudaría, así, a comprender qué papel desempeñan tales retóricas en la conformación (si es que lo conforman realmente, pues esto es lo que habría de dilucidarse) de aquello que de crítico se atribuye a los análisis geográficos que con tanto ahínco las movilizan².

Además de la dependencia epistemológica que ya hemos apuntado, la manera de darse todas estas estrategias pospositivistas ha ido generando una cierta reordenación de la disciplina según los parámetros, las preocupaciones y las agendas inherentes a los vocabularios teóricos importados o según su

y a veces histriónicas, versiones) en la geografía anglosajona desde los años setenta, así como el encuadramiento posterior, más que convergencia, en los años noventa, de todos estos intentos por salir de la "espacialidad esencialista» (ibídem) en la autodenominada «geografía crítica».

Cfr. Doel (1999) como ejemplo culminante de cómo este frenesí refundador de cierta geografía ha fiado su valor crítico a la proliferación de todo tipo de logomaquias espaciales. Que, en descargo del referido trabajo, pudiera ciertamente aducirse su naturaleza de ejemplo extremo y hasta insólito por lo apretado de la sucesión de ocurrencias retóricas criptoespaciales, y, por tanto, el ser candidato poco firme a producir algún tipo de aportación sólida o perdurable a la disciplina, no exime de la necesidad de preguntarse por el sentido de la presencia de fórmulas sospechosamente parecidas en otros trabajos acaso tenidos por más serios y merecedores de crédito, aún cuando, en realidad, asumen un esquema argumentativo idéntico.

2. Con el fin de subsanar algo de esto y para proporcionar cierta "profundidad filosófica» a los análisis disciplinarios recientes (la misma, por otra parte, que los propios geógrafos anglosajones han venido buscando en sus intentos constantes de refundar la disciplina sobre renovadas bases epistemológicas críticas y con la «teoría» como principal herramienta para ello), escribí mi tesis doctoral Sobre los cambios en las imaginaciones geográficas contemporáneas: Historiografía, epistemología y teoría en la geografía crítica anglosajona (2011). Algunos de los argumentos que aquí se presentan, de manera necesariamente sucinta, han recibido desarrollo y justificación más pausados en dicho trabajo. Que la referida "profundidad filosófica» exprese pleonasmo o cursilería es cuestión difícil de atajar, y acaso no quepa más que tomar todo esto (análisis y analizados) con irónica resignación. 
parecido con ellos. Si bien no puede afirmarse, en un sentido absoluto, que tales problemas fueran ajenos a la propia trayectoria epistemológica de la geografía, es obvia la distorsión que han ejercido sobre la tradición conceptual de las diversas escuelas geográficas, lo cual ha forzado una recreación amnésica, y a menudo casi exótica, del canon de pensamiento geográfico, es decir, sin respetar ni atender a lo propio de ese pasado, aún cuando, por supuesto, ello no implica reproducir la airada respuesta de los defensores anglosajones (o castizos, tanto da) del canon, sea éste literario, filosófico o geográfico, sino que, por el contrario, puede y debe entenderse en el marco de lo común y compartido en el más amplio horizonte epistémico de las ciencias sociales y humanas.

Quizás en ningún otro sitio se vean más claramente las consecuencias de esta pulsión por ahormar la geografía conforme a las inquietudes y a los esquemas de otras disciplinas sociales, como en las reediciones y publicaciones hechas en la última década de los manuales y de los diccionarios de conceptos o «autoridades» geográficas ${ }^{3}$. La apertura de la disciplina al diálogo con otros campos de conocimiento (y sus metodologías y teorías) no tendría que conllevar necesariamente el mimetismo, la autocolonización, ni que manifestarse como una interminable «adaptación» a la disciplina de dichos vocabularios, pues, bajo la advocación (y la reminiscencia religiosa del término no está aquí de más) del desarrollo de los componentes o de las vertientes espaciales de todos esos elementos teóricos, ha acabado por sumir, dado el vertiginoso ritmo al que se han sucedido estos procesos, a un sector importante y rigurosamente crítico de la geografía anglosajona en las mismas prácticas escolásticas en que dinámicamente languidece, valga el oxímoron, la filosofía practicada en los campus y en las editoriales de moda. A mi juicio, esto ha quedado patente en cierta práctica geográfica de las «reinserciones» de lo espacial en lo social y lo político, por aludir directamente al proyecto de Edward Soja y a la saga de reediciones posmodernas que éste ha generado, en lo que podría entenderse como una verdadera apoteosis del popurrí teórico geográfico.

Convendría pararse a pensar, por lo tanto, a qué se ha debido y cuáles han sido los efectos de esta llamativa conjunción de, por una parte, el reiterado, y

3. Véase, por ejemplo, la evolución, en las sucesivas ediciones del Dictionary of Human Geography, tanto el publicado por Oxford como el más famoso de Wiley, de la definición de ciertos conceptos geográficos, así como de la incorporación de otros nuevos, de cuño claramente filosófico o teórico-social, tenidos ahora por propiamente geográficos. La conversión de dichos manuales en publicaciones de aliento más ambiciosamente teórico es paradigmática de este proceso del que hablamos. Pensemos, por poner otro ejemplo, en el texto Key Thinkers on Space and Place, editado por los geógrafos P. Hubbard, R. Kitchin y G. Valentine, en 2004 por SAGE, y usado a menudo en las facultades anglosajonas de geografía como manual para estudiantes de primeros cursos. La ausencia de figuras como Humboldt, Ratzel o Vidal de la Blache, dignamente merecedoras, sin duda, de la sospecha del buen geógrafo crítico en busca de teoría, queda escasamente justificada si se alude tan sólo a la voluntaria falta de toda dimensión histórica en este tipo de manuales, que, en cambio, erigen a Haraway, Foucault, Deleuze o Baudrillard, entre otros muchos (incluidos geógrafos como, por supuesto, Harvey, Massey, Gregory o Soja), como figuras clave por su contribución a las «discusiones teóricas» (ibídem: 1) en torno al espacio y al lugar. 
asaz problemático, intento de convertir la geografía en una disciplina teórica, y, por otra, el olvido y la marginación de la tradición geográfica, salvo en aquellos casos, claro está, en que ésta se presenta bajo la forma de una reescritura imaginativa de la misma, esto es, aquélla que se da conforme a los cánones de la teoría contemporánea (y aquí cabe parar mientes en aquel famoso título, Geographical Imaginations, con que Derek Gregory bautizó su foucaultiana historia de la geografía). Un balance ponderadamente crítico de todos estos cambios requiere de un análisis detenido y sin componendas acerca de qué ha significado el que muchos de estos pensadores contemporáneos, como los glosados en el mencionado Key Thinkers on Space and Place, hayan sido leídos por los geógrafos como «teóricos del espacio», y en tanto que tales hayan sido importados e integrados en la disciplina, lo cual, por cierto, debe comenzar por dilucidar si dicha operación tiene algún sentido en el fondo o está, en origen, ya viciada ${ }^{4}$.

Se trata de una tarea tanto más urgente, no sólo por el propio poder de difusión y penetración de la geografía anglosajona y sus modas en el «espacio académico global» (y semejante constructo parece concitar no pocas emociones en la periferia), sino por cuanto, además, las nuevas generaciones de geógrafos se ven impelidas, para poder superar con éxito las exigencias burocráticas que conlleva el desarrollo de su carrera académica, a peregrinar por los principales centros hegemónicos de producción del pensamiento geográfico, iy esto lo dice quien mucho ha peregrinado! De modo que una comprensión crítica del marco epistemológico en que se desarrolla dicho pensamiento, y de la historia conceptual de las tradiciones geográficas con que éste se relaciona, es esencial para una recepción cabal y un juicio reposado (nacido, por qué no decirlo, de un escepticismo más corrosivo que «sano» en sus efectos —aunque muchos gusten de pensar lo contrario-) de tales modas de pensamiento, pues de ellas vemos, a menudo, más bien, una importación acrítica y un uso ciertamente retórico, que no hace sino reproducir y celebrar la propia confusión conceptual que aqueja a cierta geografía anglosajona hoy en día 5 .

4. Los trabajos de Stuart Elden sobre el uso que los geógrafos han hecho de la obra de Foucault, Lefebvre o Kant (Elden, 2001a, 2001b, 2009, 2013), las críticas de Clive Barnett a las que se aludirá más adelante, así como la propia aportación de Jeff Malpas (tal y como aquí se defenderá), son especialmente valiosos para llevar a cabo un análisis de esta tendencia a asumir como «teoría espacial» los más variopintos fragmentos de la obra de, por lo demás, respetables pensadores.

5. Huelga decir, por supuesto, que la apelación a la importancia y a la necesidad de cierta claridad conceptual nada tiene que ver con el interés por «fijar» el contenido o el significado de las categorías en cuestión, ni con cualquier otra pulsión nominalista, definitoria o disciplinaria. Más bien, al contrario, tiene que ver con la importancia de comprender en profundidad el sentido y el alcance de ciertos conceptos geográficos, así como de los problemas epistemológicos asociados a sus significados históricos, o a sus transformaciones actuales, y de las cuestiones ontológicas subyacentes. Es en todo ello donde se puede llegar a apreciar el calado político, en realidad, de ciertas categorías geográficas, y no tanto resignificándolas a través de su inserción en ciertas retóricas críticas de las cuales se da por sentado el valor político. 
Como consecuencia de esto último, se han generado una serie de lugares comunes en el pensamiento geográfico contemporáneo que pocos son los que se detienen a examinar, pues, al cabo, el éxito de cierta jerga conceptual o fórmulas teóricas que, en el mundo anglosajón, son asumidas como típicamente "críticas» no suelen levantar sospechas ni concitar recelos entre quienes se cuentan en las filas de los críticos, con lo que se da a menudo la circunstancia de que la más leve insinuación de que quizás todo esto requiriese algo más de justificación y elaboración conceptual, pues no tiene visos de la menor solidez intelectual, suele zanjarse abruptamente con una apelación, con pretensión de obviedad, a la legitimidad del uso parcial, flexible, e incluso lúdico, pero siempre en propio beneficio, de ciertas nociones o fragmentos de teorías de pensadores, si de iluminar las oscuras realidades geográficas que vivimos se trata (¿o no es acaso de suyo la geografía — se aducirá sensatamente- ciencia utilísima con vocación práctica, que sólo ha de aceptar maridajes con teorías no menos prestas a la aplicación o el acomodo?)

Cualquier lector avezado del tipo de trabajos que suelen tenerse por pensamiento geográfico en el mundo anglosajón (o geographic thinking, spatial scholarship, socio-spatial theory, critical spatial thought, pues los neologismos de este tipo han proliferado sin pudor) habrá de acabar reconociendo el valor limitado de algunas fórmulas acuñadas en estos últimos años por geógrafos de mucho renombre ${ }^{6}$. El potencial crítico de algunos de los nuevos vocabularios y de las referencias filosóficas de resonancias claramente espaciales, sobre todo las emparentadas con el posestructuralismo, ha quedado sentado con claridad palmaria en el transcurso de las décadas pasadas, aunque, a mi juicio, la intensidad de tales afirmaciones no ha ido siempre pareja de una justificación lo suficientemente sólida sobre cómo generan propiamente un pensamiento geográfico (o algo similar digo de tal consideración) las nuevas teorizaciones de los conceptos geográficos tradicionales: lugares, paisajes, regiones y fronteras ahora pensados desde el horizonte de las «ontologías planas», las geografías

6. En este tipo de trabajos, anglosajones o no, es frecuentísimo toparse con, pongamos, alguna variante sinonímica e híbrida del «Thirdspace» de Soja, aplicada a los más diversos contextos u objetos. Sin embargo, dicho concepto suele desempeñar un papel meramente ornamental, como efectivamente se constata en un examen más detallado que pone de relieve que las metodologías del análisis geográfico en cuestión suelen ser propiamente las «tradicionales», y que lo mismo cabría haber dicho sin acudir perifrásticamente a ese tipo de fórmulas teóricas, pues la propia naturaleza de los hechos investigados lleva a concluir lo que pomposamente se sintetiza a priori, a modo de píldora ontológica, en tal concepto.

Algo no del todo diferente puede decirse de otras fórmulas que han hecho fortuna en el pensamiento geográfico, como la acuñada por Doreen Massey de «geographies of responsability» (Massey, 2004), que suele ser utilizada alegremente sin que se repare en el tipo de presupuestos filosóficos que han de asumirse para que un concepto así funcione como juicio moral crítico con la realidad que denuncia (cfr. Barnett y Land, 2007, para una acertadísima crítica a dicho concepto), o sin que la propia fórmula parezca estar mínimamente conformada por las exigencias argumentativas que impone el propio campo de procedencia de conceptos de tanta solera, pero tan controvertidos, como el de «responsabilidad». 
«más-que-humanas» o las "geografías-no-representacionales», y, en general, de los postulados ontoepistémicos del posestructuralismo ${ }^{7}$.

Este déficit de justificación tiene varias dimensiones, aunque, probablemente, los geógrafos se hayan centrado hasta el momento, sobre todo, en la falta de articulación normativa de las posturas teóricas mencionadas ${ }^{8}$, abundando en cómo este hecho ha tendido a consolidar, progresivamente en la disciplina, «modos partidistas de justificación» (Olson y Sayer, 2009: 182): la discusión normativa de la fundamentación de las teorías propuestas habría sido sustituida por una mera apelación genérica al compromiso con los «valores» o fines que sustentan o persiguen tales teorías (como si los valores sólo pudieran sostenerse dogmáticamente o fueran de por sí el único fin loable de toda actividad académica), o bien dándose la simple suposición de una adhesión implícita o espontánea - por parte de los lectores o de otros grupos- a tales formas de fundamentación que, por consiguiente, no parecen necesitar de elaboración o discusión alguna, pues son asumidas como un mero apriorismo sin más matices?.

Aquí me centraré únicamente en la dimensión conceptual de este rasgo del pensamiento geográfico contemporáneo, es decir, en explorar la posibilidad de que su contenido conceptual pueda ser explicitado, defendido y argumentado con la solidez que se requeriría para que tal conjunto de trabajos puedan ser tomados como algo cabal, y confrontados, por tanto, en un nivel argumentativo equiparable al del estatus cognitivo que todas estas nuevas teorizaciones se han arrogado. Que la autodenominada «teoría» o "pensamiento geográfico» críticos existen como tales y gozan de gran prestigio en el mundo anglosajón es algo difícilmente refutable. No podría decirse con igual rotundidad, no obstante, que su marca distintiva sea su rigor conceptual o su solidez argumentativa y filosófica, ni sensatamente puede pretenderse tal cosa, ya que, más allá de cierto punto razonable, tales propiedades les resultan a los geógrafos más bien

7. Los conceptos o las fórmulas mencionadas hacen referencia a debates geográficos recientes, como los relacionados con el "giro topológico» al que el propio Malpas se ha referido críticamente (véase nota 3 del texto de Malpas traducido en este mismo número, o cfr. Collinge, 2006; Lorimer, 2005, o Thrift, 2008, como ejemplos de las corrientes o de las tipologías aquí citadas). El interés y el valor de cada uno de ellos presenta una gran variabilidad, pero su sentido general no puede desligarse de lo que, sin duda, ha sido un proceso de proliferación conceptual, evidente en la geografía anglosajona, surgida con demasiada frecuencia de un desenfrenado, aunque rentabilísimo, uso de la maquinaria retórica posestructuralista al servicio de la ontología espacial.

8. Cfr. las críticas de Wyly (2009), Barnett (2006, 2008a, 2008b, 2012) y Olson y Sayer (2009).

9. En la propia geografía anglosajona crítica, aún son escasas, aunque contundentes, las voces que se alzan contra esta "clausura de la reflexión normativa» (Barnett, 2010: 248) establecida desde hace décadas y reproducida en ciertos hábitos argumentativos propios de la teorización crítica en geografía. Como acertadamente ha demostrado Sayer (2000: 169), no se trata, por supuesto, de un problema de la propia teoría crítica, sino de la manera en que ciertos «estudios empíricos críticos de objetos sustantivos», como la geografía, han desplegado esas formas de crítica. Cfr. Corbridge (1998), Barnett y Low (2004), Agnew (2003: 604 y s.) para una argumentación similar. 
estorbos y distracciones inútiles que les alejan de otros fines prácticos sin duda más loables y acordes a su condición. El valor estratégico y la eficacia retórica de los conceptos espaciales utilizados en estos trabajos radica en ser vehículos de la crítica de ciertas tendencias económicas, sociales y políticas del mundo contemporáneo, y probablemente como tales han de ser evaluadas. Si resulta correcto o no calificarlas de pensamiento geográfico o de "teorías espaciales» parecería una trivialidad (si es que no un empeño más bien oscuro), al lado de aquello que es su verdadera fuente de valor. Y, sin embargo, de nuevo, el maridaje de estos trabajos con la teoría requiere ser aclarado, pues es obvio que dicho valor estratégico no conlleva necesariamente un tratamiento sustantivo de los conceptos geográficos movilizados en tales críticas. Y aunque se ha reiterado la necesidad imperiosa de reteorizar tales conceptos como requisito esencial para obtener de ellos la funcionalidad crítica buscada (el caso prototípico aquí sería la obra de David Harvey o de Doreen Massey), lo que dicha teorización significa dentro de un marco epistemológico constructivista como el que ha dominado en la geografía humana pospositivista no está del todo claro, pues, en puridad, dicho marco impone unas restricciones importantes a la reflexión ontológica acerca de tales conceptos e impide tratarlos como ideas sui géneris, ya que estos son, al cabo, meros constructos de fuerzas económicas, sociales o culturales, cuyas concreciones espaciales son el verdadero objeto relevante de análisis ${ }^{10}$.

Ninguna de estas consideraciones que estoy haciendo tendría sentido ${ }^{11}$, si no fuese precisamente porque han sido los propios geógrafos críticos los que, en las últimas décadas, han asumido, proclamado e insistido hasta la saciedad en la necesidad de que fueran ellos mismos los encargados de generar teorizaciones de los conceptos geográficos. Semejante actitud ha puesto a la geografía, como disciplina y como práctica investigadora, en una situación paradójica bastante difícil de resolver hoy en día, si hemos de responder a qué cosa sea en puridad algo así como una teorización "geográfica» de tal o cual cosa, y esto no sólo por la más socorrida razón de que la teoría implica de suyo un grado de abstracción que casa mal con los propios fines y la naturaleza misma de aquello que estudia la geografía humana (al menos, una vez que lo exclusivamente cuantitativo parece haberse descartado como epistemología crítica).

10. Así podría formularse con acierto el núcleo de la crítica que Jeff Malpas hace en su texto ya aludido «Pensar topográficamente: Lugar, espacio y geografía».

11. Pues, evidentemente, como ya he insinuado antes, la geografía no tiene ni tendría por qué dedicarse a elaborar filosóficamente el contenido de los conceptos que usa, y, de hecho, la propia práctica del análisis histórico del pensamiento geográfico pone en juego formas de reflexividad, como tantas veces ha insistido Vincent Berdoulay, que miran a las prácticas de la geografía en tiempos pasados y presentes de forma capaz de explicitar y analizar el contenido conceptual inherente a las mismas, sin que dicha hermenéutica guarde relación clara con lo que la geografía anglosajona ha instaurado como práctica habitual de pensamiento geográfico (reconvertido en fulgurante spatial thinking). El trabajo de Oriol Nel-lo sobre la obra de Francesco Indovina, publicado en la colección «Espacios Críticos» de la editorial Icaria, puede ser un ejemplo laudable de esta hermenéutica a la que me refiero (Nel.lo, 2012). 
Cualquier forma de análisis geográfico de tal o cual fenómeno estará entreverada, por supuesto, de elementos teóricos (háganse estos explícitos o no), pero tal forma de análisis implica necesariamente que se respeten y se pongan en práctica algunas propiedades epistemológicas consonantes con la naturaleza de lo geográfico, como, por ejemplo, la atención a las formas particulares de darse espacialmente los fenómenos en cuestión. Son ese tipo de características epistemológicas las que, en última instancia, hacen distinto el análisis geográfico del histórico o del filosófico, y lo que, asimismo, supone que, más allá de un número limitado de generalidades más o menos vagas acerca de la imbricación necesaria de lo espacial y lo social, no pueda decirse cabalmente mucho más, en los términos teóricos pretendidos, de dicha imbricación, y que, por tanto, una teoría espacial que se presenta bajo los supuestos epistemológicos constructivistas reinantes hoy en día resulte ser una cosa cuando menos huera, si no pretenciosa y, al cabo, algo falaz ${ }^{12}$.

Es precisamente ante este estado de cosas que considero la obra del filósofo Jeff Malpas (cuyo texto "Pensar topográficamente: Lugar, espacio y geografía» antecede y da pie a este artículo) especialmente relevante en esta ardua tarea de no sólo reflexionar sobre los conceptos geográficos, sino, sobre todo, de hacerlo a contracorriente de las creencias y los entusiasmos dominantes, es decir, cuestionando algunos de los lugares comunes que la difusión de cierto pensamiento geográfico anglosajón ha generado. Y creo que es justamente al hilo de las consideraciones precedentes como tiene que interpretarse el diagnóstico de Malpas de que la geografía todavía espera un "giro crítico» (uno que implique mayor análisis y modestia intelectual) en relación con su actitud teórica respecto de los conceptos de espacio y lugar; del mismo modo que ha de entenderse en este sentido la exhortación, que de otra manera podría pasar por insolente, a que la geografía lleve a cabo un "giro topográfico" como aquel que el propio Malpas propone, aunque la conveniencia de esto segundo sea un asunto más discutible.

A pesar de las diferentes direcciones en que se podría concretar esta tarea crítica $^{13}$ y de los diversos modos en que la filosofía de Malpas resulta relevante para dicho proyecto (aparte, por supuesto, de la propia contribución de su trabajo a la filosofía, algo de lo que aquí no puedo ocuparme), en los siguientes apartados me centraré únicamente en dos aspectos de su obra que inciden

12. Véase Sayer (2000, sobre todo, p. 105-154) para este tipo de crítica.

13. Además de la tesis doctoral antes mencionada, he tratado de abordar algunas dimensiones de estos problemas señalados del pensamiento geográfico y de su epistemología e historia reciente en otros trabajos (Puente, 2009, 2011, 2013). En ellos, he tratado de analizar tanto los debates generados en geografía sobre el denominado "giro espacial» y el sentido de los términos en que se han planteado dichos debates, como las concepciones predominantes de «lo político» en la geografía crítica anglosajona actual, además de la problemática recepción y los usos recientes de ciertos pensadores en dicha geografía. Se trata, tan sólo, de aportaciones parciales a la reflexión y a la escritura de una historia de los conceptos geográficos contemporáneos que, una vez que la propia disciplina se ha puesto a sí misma en la tesitura de ser parte activa del pensamiento espacial actual (signifique aquello lo que signifique), si no quiere caer en hacer meramente una suerte de seguidismo acrítico, ha de elaborarse filosóficamente, para lo cual probablemente no esté de más algo de humor y polémica. 
directamente, y de manera crítica, en los modos de argumentación que la referida geografía ha venido utilizando en las últimas décadas.

En primer lugar, abordaré la reflexión y la teorización sobre el concepto de lugar que ha llevado a cabo Malpas, entendiéndolo desde su perspectiva de "pensamiento topográfico» y tratando de poner de relieve su particularidad, al compararlo con los modos en que ciertas corrientes de la geografía han tratado dicho concepto. En segundo lugar, glosaré algunos aspectos de la incisiva crítica que Malpas ha realizado al predominio de los esquemas constructivistas en el pensamiento geográfico contemporáneo, por cuanto generan discursos y formas de análisis que, al haber asumido que el concepto de lugar tiene de suyo un carácter política y éticamente problemático, impiden comprender su naturaleza y su necesidad en tanto que categoría fundamental, más allá, por tanto, de los efectos que las distintas manifestaciones históricas de la conexión entre política y lugar puedan tener.

Considero que centrarse en estas dos cuestiones señaladas, aunque sea de manera necesariamente breve, no sólo puede ayudar a esclarecer el significado de algunas de las consideraciones que Malpas realiza en el artículo que antecede a éste, y, por tanto, el sentido general de su propuesta de "pensamiento topográfico» con respecto a la geografía, sino que, además, ilustra en cierta manera la importancia de cuestionar algunos de esos lugares comunes a los que me he venido refiriendo en estas páginas.

\section{El lugar y la estructura topológica de la experiencia}

La obra del filósofo australiano Jeff Malpas destaca, en el panorama intelectual contemporáneo, por su particular integración de temas y perspectivas de las tradiciones analítica y continental, habiendo desarrollado progresivamente su idea de "pensamiento topográfico» (o su noción de la filosofía como topología) a partir de fuentes, tanto fenomenológicas y hermenéuticas, como de las principales corrientes de la filosofía analítica del lenguaje y de la mente. Su trabajo y su constante reflexión sobre la noción de lo trascendental, así como su original tratamiento y combinación de otros conceptos tales como, por una parte, ground, unidad o límite y, por otra, memoria, identidad o pertenencia ${ }^{14}$, le han llevado a establecer sólidos puentes entre las preocupaciones hermenéuticas de las tradiciones europeas del pensamiento y los modos y las temáticas analíticas de la filosofía anglosajona. Su temprano interés por la filosofía de la historia y su sostenida interrogación ontológica acerca de los conceptos centrales de la experiencia humana (entre ellos, de manera destacada el de lugar) han hecho cristalizar su pensamiento en torno al triángulo formado por tres autores aparentemente alejados entre sí, como son Donald Davidson, por un lado, y Hans-Georg Gadamer y Martin Heidegger, por el otro. Dicho diálogo surge, sin embargo, de manera natural y fluida en la obra de Malpas, precisa-

14. Algunos de estos conceptos han sido explícitamente tratados por el autor en trabajos como Malpas (1999a: 92-108, 2012a: 73-95) para el caso de los tres primeros, y Malpas (1999a: 157-193, 2010a) y Malpas y Miller (2009) para los otros mencionados. 
mente porque él encuentra en estos autores el rasgo común de ofrecer distintas facetas y elementos de un tratamiento filosóficamente robusto de las ideas de lugar, emplazamiento y topografía ${ }^{15}$, pues, como él mismo defiende en la sin duda original lectura que hace de dichos pensadores, la de lugar es una de las categorías centrales del pensamiento de estos filósofos.

Ha sido precisamente el trabajo sobre los aspectos «topográficos» del pensamiento en estos autores (es decir, todo aquello relacionado con la idea de lugar, entendida desde una perspectiva de la espacialidad humana) y, de manera destacada, la interpretación de Heidegger como pensador del lugar (Malpas, 2006), lo que ha llevado a Malpas a desarrollar progresivamente su idea de pensamiento topográfico: una perspectiva integradora, de tipo holístico (capaz, por tanto, de mostrar la interconexión de los conceptos sin caer en formas cualesquiera de reduccionismo), que refleje la propia estructura topológica de la experiencia y la comprensión humanas, intentando superar así los problemas de subjetivismo o internalismo que presentaban las perspectivas fenomenológicas y metafísicas (tan presentes en la geografía, por ejemplo: la humanística) ${ }^{16}$.

Lo "topológico" en esta aproximación tiene un sentido doble y hace referencia, por un lado, al carácter «emplazado» del conocimiento y de la experiencia (como aquello cuyo darse implica siempre tener lugar, por lo que es través de este hecho fundamental de su darse localizadamente como deben entenderse ambos), y, por otro lado, a una estructura «integrada», consistente en la interconexión de una serie de conceptos esenciales (como los de objetividad, subjetividad, espacio, tiempo, acción, etc.) que no pueden derivarse ni reducirse unos a otros, así como tampoco explicarse sin atender debidamente a su relación con los otros en cuestión ${ }^{17}$.

15. Esta tarea ha sido llevada a cabo a través, sobre todo, de la elaboración de los conceptos davidsonianos de "triangulación» y «localización», relacionados con su teoría de la "traducción» e «interpretación radical» (cfr. con los trabajos de Malpas sobre Davidson, en Malpas, 1992, 1999c, 2011b), y de la propia «topología del Ser» en Heidegger (véase, a este respecto, Malpas, 2006, 2007, 2008, 2012a). Asimismo, puede remitirse a Malpas (2005, 2010a, 2010b, 2014) para sus estudios sobre Gadamer y la aportación de la hermenéutica. Una reflexión sobre la relación entre estos tres autores y sobre los términos en que puede establecerse su comparación y su centralidad para la perspectiva topológica de Malpas (dada la interconexión que éste establece entre la reflexión ontológica, la interrogación hermenéutica por la estructura de la comprensión y el significado, y las preocupaciones analíticas externalistas y holistas sobre la estructura del lenguaje, ancladas todas ellas en un interés sobre cuestiones ontológicas subyacentes) puede encontrarse en "Topology, Triangulation and Truth» (Malpas, 2012a: 199-223) y en Malpas (1999d).

16. Cfr. Malpas (2002 y 2004b) para una explicación más detenida sobre el sentido y las fuentes filosóficas de su idea de holismo.

17. Para una explicación más detallada del sentido de lo topológico, véase el texto de Malpas "The Place of Topology» (2012a: 43-70). Existe un tercer sentido en que lo topológico, como estructura también de la compresión, afecta de manera profunda a la propia idea de pensamiento, de ahí que el proyecto de Malpas tenga también consecuencias importantes para la filosofía como reconfiguración del lugar mismo del pensamiento (véase, a este respecto, por ejemplo: «The Topos of Thinking» $y$ «Philosophy's nostalgia», en Malpas, 2012a: 13-21 y 161-175, respectivamente). 
Es la necesidad de dar cuenta de la complejidad de la espacialidad humana «tal y como surge en relación con la implicación de los seres humanos en el mundo" (Malpas, 1999a: 43) lo que inspira el tratamiento que Malpas hace del concepto de lugar, con el fin de integrar los distintos elementos que el análisis de este concepto moviliza y que, normalmente, han solido aparecer disgregados.

En este sentido, la obra de Malpas camina en la dirección ya emprendida por el también filósofo Ed Casey, en trabajos de los años noventa como Getting Back to Place o The Fate of Place, o por el geógrafo Robert Sack, quien, en su Homo Geographicus: A framework for Action, Awarness, and Moral Concern, de 1997, trataba de desarrollar también un enfoque integrador que presentara algunas similaridades con la propuesta de Malpas ${ }^{18}$.

Asimismo, la insatisfacción con la mayoría de la literatura espacial (no sólo la propiamente geográfica, sino también otro tipo de discursos en las ciencias humanas y sociales asociados a lo que, en las últimas décadas, se ha llamado el "giro espacial») es lo que ha llevado a Malpas a abordar de manera más sistemática, como hizo en su obra de 1999 Place and Experience: A Philosophical Topography, la reflexión sobre el concepto de lugar. Al inicio de dicho trabajo, afirmaba:

El carácter disperso de tantísimas explicaciones acerca del lugar en tantas disciplinas, en tantos diferentes escritores y con respecto a tal variedad de materiales y temas, proporciona un impulso hacia el desarrollo de una aproximación más integrada del lugar [...]. Pero debe también quedar claro que si el lugar ha de considerarse efectivamente como un concepto por sí mismo, más que un cajón de sastre adecuado para aquello que parece ser solamente un conjunto de ideas y problemas escasamente conectados, entonces, el desarrollo de una explicación más integrada es esencial. Sólo en el marco de una explicación tal sería posible dar contenido a la idea de que el grupo de problemas e ideas que encontramos en las discusiones sobre el lugar están, de hecho, significativamente relacionadas. (1999a: 31. Traducción propia)

Este doble impulso hacia una renovada, más compleja y unitaria comprensión del «lugar» es lo que conforma la crítica que Malpas viene haciendo de manera sostenida desde hace años al tratamiento reduccionista que, tanto en geografía como en algunas otras ciencias sociales y humanas, este concepto ha solido recibir. Bien sea el reduccionismo físico de la tradición filosófica moderna (propio también de las formas cuantitativas de geografía), donde el lugar se entiende como pura localización; bien las formas de subjetivismo de la fenomenología y de la geografía existencial y humanística, en que la concepción del lugar acaba dependiendo enteramente de la respuesta emocional de los

18. Para entender la particularidad y los matices de la aportación de Malpas, así como su diferencia respecto de estas otras referidas, puede consultarse la bibliografía específica en torno al debate suscitado por sus trabajos entre filósofos y geógrafos (véase Cameron, 2004; Stefanovic, 2004; Casey, 2001; Relph, 2008; Young, 2011; Crowell, 2011; Beistegui, 2011, o Elden, 2003; así como Malpas, 2001a, 2004a y 2012a: 43-70, donde responde a algunas de estas críticas). 
sujetos al medio, o bien, ya más recientemente, otras formas de reduccionismo cultural, social o económico asociado a las posturas constructivistas que explican el lugar como mero producto de procesos de diversa naturaleza; en todo este tipo de aproximaciones, Malpas insiste en criticar la tendencia que expresan a confundir o solapar los conceptos de espacio y lugar, que, a menudo, se utilizan de forma intercambiable, sin contenido conceptual o entidad propia, al depender, además, de un marco explicativo que impide, en última instancia, realizar un tratamiento sustantivo de los mismos.

La topografía filosófica de Malpas ha de entenderse, en este sentido, como una suerte de trabajo sobre la relación entre los conceptos esenciales de la espacialidad humana, que intenta dotar al «lugar» de una «fundamentación filosófica más adecuada" (Malpas, 1999a: 197). Se trata, por tanto, de un trabajo previo y compatible, en muchos casos (no en todos, eso sí), con otro tipo de estudios y análisis sobre lugares concretos. En este sentido, no pueden establecerse implicaciones metodológicas simples o directas entre el tratamiento ontológico sobre la categoría de lugar que propone Malpas y la investigación geográfica, aunque, ciertamente, son dos niveles conectados ${ }^{19}$. La crítica de Malpas se dirige contra los discursos con pretensiones explícitamente teóricas sobre la idea de lugar que, sin embargo, cuando son examinados de cerca, impiden, por defectos internos de su propia argumentación y de los marcos ontoepistémicos subyacentes, la posibilidad de realizar una reflexión sobre el lugar en tanto que categoría general. Tal y como recientemente ha afirmado Malpas:

Por supuesto, los topoi específicos existen y se dan en el mundo, pero el topos en tanto que tal viene a nombrar el acontecer mismo del mundo como aquello que ocurre en y a través del lugar. [...] El topos no nos remite a un subjectum, sino al ámbito de interrelación en que las propias cosas pueden aparecer. [...] En cierta medida, cabe decir que el concepto de topos es anterior a otros, no en el sentido de que sea subyacente a estos, sino por cuanto es aquello con y en lo que cada uno de los demás conceptos está relacionado, y a través de lo que cada uno de ellos encuentra su propia condición de estar relacionado con los demás. Por lo tanto, el lugar abarca lo corporal y lo medioambiental, lo espacial y lo temporal, lo objetivo y lo subjetivo (aunque no se deje abarcar completamente por cada uno de ellos). Y esto es así, además, no sólo por cómo todos esos elementos mantienen su propia relación con el lugar, sino, sobre todo, en la medida en que todos ellos comparten una estructura "topológica» similar. (Malpas, 2012a: 55-56. Traducción propia) ${ }^{20}$

19. Cfr. Malpas (2001b) sobre la relación entre estos dos niveles. La pregunta por la diferencia que, en la práctica del análisis geográfico, supone la postura de Malpas surge casi de manera instantánea de la boca del geógrafo, pero acaso sea tan improcedente y estéril plantearla en términos generales como esos interminables debates, igualmente vagos, sobre las consecuencias pretendidamente prácticas que se busca extraer de tal o cual forma de pensamiento.

20. Para comprender el sentido de todo esto (y superar el aire ciertamente tautológico que este enfoque presenta a primera vista — no en vano los vicios analíticos refuerzan aquí los vicios continentales-), resulta necesario acudir al desarrollo que de las nociones de «unidad» y «complejidad» del lugar hace Malpas en su obra Place and Experience (1999a). 
Precisamente, la clave de la diferencia con respecto a los tratamientos tradicionales del lugar en la geografía humanística radica en el manejo de una estructura conceptual que trata de dar cuenta de la integración de estos distintos elementos sin que quepa reducirlos a meros componentes de la subjetividad. En los trabajos clásicos de geógrafos como Edward Relph (Place and Placelessness), Éric Dardel (L'Homme et la terre) o Yi-Fu Tuan (Space and Place, Topophilia) o en la perspectiva fenomenológica más asociada a las geografías del comportamiento (en los trabajos de Anne Buttimer o David Seamon), el lugar es entendido como un "centro de significado", donde intenciones y vivencias humanas hallan su configuración específica. Este tipo de trabajos se han orientado, fundamentalmente, a la cuestión de la pertenencia y la identificación, por lo que el lugar ha tendido a comprenderse como un ámbito de producción de sentido, valor y cuidado (o sus contrarios, aunque hogar y lugar han solido asimilarse en estos enfoques), de manera que se entiende que son esencialmente los vínculos afectivos y las tonalidades emocionales los que determinan la construcción del sentido de los lugares para los individuos ${ }^{21}$.

Aunque, en esta literatura, la conexión entre lugar y experiencia ha sido central (algo muy relevante desde la óptica de la crítica que formulaban a la «deshumanización» de los paisajes contemporáneos en el contexto de las transformaciones urbanas del mundo global), a juicio de Malpas, estos geógrafos han sostenido una comprensión inadecuada de dicha relación, de la que se derivan las propias insuficiencias de su idea de lugar, dependiente en exceso de una idea subjetivista de la experiencia, que genera, a su vez, una visión del lugar como una mera «aprehensión subjetiva de la localización» (Malpas, 1999a: 37).

Éste es uno de los motivos por los cuales el análisis de la espacialidad humana (y de la relación entre objetividad y subjetividad en la estructura de la experiencia y, por tanto, también, entre lugar y subjetividad) es central en la reflexión que Malpas lleva a cabo en su obra Place and Experience (1999a) ${ }^{22}$. Como afirma el autor:

Aunque sea cierto el caso de que el lugar no se constituye con independencia de la subjetividad — del mismo modo que no se constituye con independencia del mundo físico-, tampoco éste depende de la existencia de un sujeto o de unos sujetos independientes. El lugar es, en cambio, aquello en lo que,

21. Para una exposición más pormenorizada de estas perspectivas humanísticas del lugar, véase Ley y Samuels (1978). Algunas de estas cuestiones están tratadas con mayor detenimiento en mi tesina titulada Espacio, lugar y experiencia: Aproximación a un debate contemporáneo (2007). La crítica de Malpas a esta idea humanista del lugar tiene que ver, fundamentalmente, con limitaciones propias de la manera en que el enfoque fenomenológico es usado por estos geógrafos (cfr. Malpas, 1999a: 9 y 30-32 para este particular).

22. No podemos entrar a discutir aquí los aspectos concretos de las tesis que Malpas sostiene en esta obra, ni su relevancia filosófica propiamente, aunque sí es importante subrayar la manera en que Malpas integra en su reflexión sobre el lugar las tesis externistas a partir de las aportaciones de filósofos contemporáneos como Davidson (Essays on Actions and Events), Strawson (Individuals), Evans (Varieties of Reference), McDowell (Mind and World), Campbell (Past, Space and Self) o Gibson (The Ecological Approach to Visual Perception), entre otros. 
y con respecto a lo cual, la subjetividad se establece ella misma —el lugar no está fundado en la subjetividad, sino que es más bien aquello en lo que la subjetividad se funda- De modo que no puede decirse que haya primero un sujeto que aprehende ciertas características del mundo en términos de la idea de lugar, sino que, más bien, la estructura de la subjetividad se da en y a través de la estructura del lugar. La conexión de la subjetividad con el lugar apunta a [...] la necesidad de ver la subjetividad como algo relacionado con la agencia y la espacialidad corporal y, por lo tanto, como algo constituido en relación con una estructura que se extiende más allá del sujeto para abarcar el mundo de los objetos, los acontecimientos y las personas. (Malpas, 1999a: 35. Traducción propia)

Básicamente, Malpas realiza una inversión de los términos de la relación entre experiencia y lugar, tal y como ésta era asumida en la geografía humanística. Con ello, asigna cierta prioridad ontológica a la categoría de lugar, por cuanto el lugar es aquello que permite el despliegue de la estructura integrada de la experiencia, dotándola precisamente de su carácter topológico. Establece así que si, efectivamente, el lugar ha de ser, como es el caso, estudiado en relación con la experiencia, no lo es porque el lugar sea resultado de la experiencia subjetiva, sino porque, al contrario, el lugar es, precisamente, la compleja estructura que genera y permite la experiencia (la subjetividad, la objetividad, la agencia, etc.), pues es su condición misma de posibilidad ${ }^{23}$.

La distinción que Malpas realiza (Malpas, 1999a: 44-71) entre espacio subjetivo, espacio alocéntrico y espacio objetivo, así como el análisis detenido de la relación entre ellos, es central para sostener su tesis. El primero de los referidos sería un tipo de espacio ordenado egocéntricamente, es decir, a partir del animal (racional o no) y de la interacción que éste establece con el medio según sus fines, sus necesidades, etc. El segundo ${ }^{24}$ se refiere a un tipo de espacio organizado a partir de ciertas características o elementos destacables del propio medio, independientes del animal en cuestión, y que pueden, por tanto, servir para definir un marco que localice puntos de manera externa a la ubicación concreta de éste, algo que resulta necesario para poder orientarse en semejante medio. Asimismo, puesto que la explicación del comportamiento de tal animal ha de incluir necesariamente alguna referencia a dicho espacio, el hecho de que el mencionado animal muestre ciertas habilidades corporales es prueba de que tiene algún tipo de manejo o aprehensión práctica (no conceptual) del espacio, sin la cual no le sería posible realizar el movimiento coordinado, ni la estructuración de su actividad.

Frente a estos dos tipos, el espacio objetivo es un espacio abstracto, donde se produce la coordinación de las distintas perspectivas que surgen de las diferentes localizaciones de los animales (esta vez sí, racionales) situados en

23. Condición material, no formal, de posibilidad (véase Malpas, 2001a: 233 y s.).

24. Traduzco aquí directamente el concepto allocentric space, aunque quizás fuera mejor hablar de «espacio geocéntrico o exocéntrico» según las otras denominaciones anglófonas (exocentric space o geocentric space) para el mismo término, tal vez más elocuentes. 
el mismo, pero sin que quepa dar prioridad a ninguna de esas ubicaciones, sino, al contrario, permitiendo la integración de esa multiplicidad de posiciones. De ahí que el espacio objetivo sea también intersubjetivo, en virtud, precisamente, de esta coordinación de todos los espacios subjetivos, algo que no se produce en el espacio alocéntrico. La distinción y la relación entre estos tipos de espacio es fundamental desde el punto de vista de la comprensión de lo que significa tener, por un lado, algún tipo de manejo práctico del espacio (o aprehensión del espacio) y tener, además, por otro, un manejo conceptual del mismo o un concepto de espacio (como el que implica, por ejemplo, la capacidad de representación cartográfica) ${ }^{25}$. La manera interconectada en que se da la emergencia de objetividad y subjetividad en la experiencia es clave para la comprensión de la estructura de la espacialidad humana, además de cómo, en el comportamiento, se produce la adquisición interdependiente de esas distintas variantes espaciales, algo de nuevo esencial si de reinterpretar la relación entre experiencia y subjetividad se trata, como en el caso de Malpas, pues esto pone de relieve la imposibilidad de llevar a cabo un enfoque que trate de explicar alguno de estos elementos reduciéndolo a otro (Malpas, 1999a: 62-63). De la misma manera, las características que Malpas atribuye al lugar (complejidad, unidad, apertura y limitación, fragilidad y alterabilidad, tenacidad o carácter recalcitrante) han de entenderse desde este esquema y, como consecuencia, por tanto, de la particular conexión entre los diferentes tipos de temporalidad y de espacialidad que se articulan por medio del lugar.

Resulta claro que la modulación de estas propiedades generales del lugar depende de las condiciones materiales según la particular configuración geohistórica y social en que tales lugares se concreten, lo cual permite una variada forma de darse la combinación de tales propiedades (incluida la práctica supresión de alguna de ellas). Sin entender algo del sentido de la relación entre lugar y lugares, parece difícil realizar un pensamiento geográfico, aunque tampoco un análisis geográfico, que se sepa comprender la diversidad de las formas de unidad del lugar. De ahí, por ejemplo, lo impropio de buena parte de la secuela

25. Las expresiones inglesas que traducimos aquí son «to have a grasp of space» $\mathrm{o}$ «to have a capacity to employ some spatial framework» (Malpas, 1999a: 46 y s.) y están relacionadas con la propia postura de Malpas respecto a la cuestión, en filosofía de la mente, de la distinción entre el contenido conceptual y no conceptual de la experiencia, que él prefiere enfocar hablando mejor de habilidades conceptuales y habilidades no-conceptuales, con el fin de responder mejor al propio carácter integrado de la experiencia y la importancia que él mismo da a la interrelación de ambos tipos de habilidades para el caso de la espacialidad (cfr. Malpas, 1999a: 47). La relevancia de la distinción entre espacio alocéntrico y espacio objetivo se entiende, fundamentalmente, por su relación con este hecho, pero también resulta importante en el trabajo de Malpas de cara a subrayar que el espacio objetivo, aunque vaciado de las percepciones particulares de los sujetos, no está separado completamente de la experiencia, sino que nace precisamente en el engarce y el movimiento de la objetividad y la subjetividad propios del ser humano. Cfr. Malpas (1999a: 66-69) sobre la posibilidad del carácter estrictamente no experiencial del espacio objetivo y de defender, al mismo tiempo, el rol esencial que éste tiene en la estructuración de la experiencia. 
geográfica de los análisis antropológicos basados en la noción de no-lugar de Augé, que tan frecuentes han sido en este último lustro ${ }^{26}$.

\section{El constructivismo en la cultura epistémica contemporánea y el argumento contra el lugar}

La mera afirmación de esta relación entre lugar y lugares implica, no obstante, que existen dos niveles de análisis que no sólo son complementarios, sino que también han de reconocerse en su respectiva relevancia y practicarse en sus propios términos. Sin embargo, los modos argumentativos y los usos retóricos a los que el denominado "giro espacial» nos ha acostumbrado impiden que, como insiste Malpas en su texto «Pensar topográficamente: Lugar, espacio y geografía», pueda realizarse un tipo de análisis general como el expuesto aquí, ya que las categorías topográficas se convierten en poco más que en «meras funciones de lo social y lo político» (ibídem), cuya teorización depende exclusivamente del análisis particular de las formas en que espacios y lugares han sido construidos por fuerzas socioeconómicas más amplias, lo cual, como ya dijimos, dota a estas categorías de un estatus teórico cuando menos paradójico dentro de los marcos constructivistas.

Teniendo esto en cuenta, se entiende mejor el sentido y la propiedad del trabajo de crítica y cuestionamiento que Malpas ha realizado acerca de los límites que las argumentaciones constructivistas suponen respecto de la reflexión del lugar, que se ha concretado en el análisis de dos movimientos que, aunque diferentes, han convergido en el reciente "giro espacial» en cuanto al sentido y al potencial crítico de las posturas que los sustentan. Por un lado, Malpas ha puesto de relieve las confusiones y los equívocos sobre los que se han articulado lo que él ha denominado «argumento contra el lugar» ${ }^{27}$, es decir, la tendencia

26. El libro Sprawling Places, de David Kolb (2008), resulta ilustrativo, en este sentido, por cómo ha sabido sortear algunos de los tópicos que, con puntual asiduidad, aparecen en la literatura geográfica mencionada. De hecho, la crítica heideggeriana a la condición moderna (cuyo tono resuena en el tipo de análisis geográficos que acabo de criticar), expresada en la propia meditación del filósofo de Messkirch sobre la técnica y sobre el sentido de la obra de arte, ha de entenderse según lo comentado acerca de las propiedades del lugar, es decir, atendiendo a cómo la modernidad tecnológica genera una determinada configuración de la espacialidad y la temporalidad (por el ordenamiento que ejercen los sistemas tecnológicos sobre las capacidades y las disposiciones para la acción), de tal modo que en dicha época ciertas características del lugar adquieren prioridad sobre otras. Este enfoque resulta más oportuno para un análisis de la experiencia geográfica contemporánea, y no, insistimos, el de los «no lugares» o el de cierta lectura ecologista que se ha hecho de Heidegger. (cfr. Malpas, 2012a: 60). Es en esta misma línea como han de entenderse los comentarios que, sobre la globalización, hace Malpas en su artículo en este número, y la relevancia, por tanto, que tiene una comprensión del lugar desde la estructura de la espacialidad del ser humano, y no como mero producto de ciertos procesos socioeconómicos.

27. En inglés, «the case against place». Es sobre todo en su libro Ethos and Topos: On the Ethics and Politics of Place, todavía en preparación, donde ha desarrollado con más extensión este análisis y donde aparecen más claramente sus quejas contra los geógrafos críticos contemporáneos (también puede verse Malpas, 2012b, 2012c en este mismo sentido). 
a considerar que el lugar es un concepto en sí mismo ética y políticamente problemático, y que toda aserción de la conexión de la identidad con el lugar, o de la determinación de ésta por aquél, es necesariamente excluyente y genera o deriva de posiciones reaccionarias. Esta acusación de "parroquialismo» y de conservadurismo se puede encontrar claramente en los trabajos iniciales de Massey (1993a, 1993b, 1994, 1995) y Harvey $(1993,1996)$ bajo la forma de un argumento antiheideggeriano. Semejante tipo de crítica en la geografía ha sido el punto de partida para un enfoque subsiguiente basado, o bien en el rechazo del concepto mismo de lugar (y su sustitución por otro tipo de categorías geográficas, más asociadas al espacio), o bien en su reducción, con lo cual aparece como un elemento derivado y dependiente de otros procesos o categorías más importantes, que, al cabo, son lo que importa teorizar (y lo que proporciona los elementos que hacen que tal enfoque pueda tener la apariencia de una teoría del espacio ${ }^{28}$.

Por otro lado, Malpas ha analizado y criticado el tipo de mecanismos constructivistas que, a menudo, configuran estos discursos contrarios al lugar, no sólo para desmantelar dicha conexión y cuestionar el carácter supuestamente problemático del concepto de lugar (y negar, además, que el «abandono» de la categoría de lugar sea realmente una posibilidad conceptual), sino también para mostrar, asimismo, los límites que este tipo de tratamientos reciben a la hora de intentar generar una reflexión sólida sobre el «lugar», pues son incapaces de hacerse cargo de la necesidad ontológica del mismo.

La asunción de que el lugar es meramente un constructo social y que, por tanto, como afirma Harvey (1996: 293-294): «la única cuestión interesante que tiene que plantearse es la de a través de qué tipo de procesos sociales se construye el lugar», es uno de los más persistentes lugares comunes del pensamiento geográfico crítico contemporáneo ${ }^{29}$. En parte, éste no es sino el resul-

28. Que la supuesta teorización de las categorías geográficas de que se trata depende, en la mayoría de los trabajos de geografía crítica, del significado de la categoría de lo político - 0 de cualesquiera elementos que sean los definitorios de los enfoques defendidos- que estos geógrafos movilizan, es algo no demasiado difícil de comprobar (ésta es la tesis, al menos, que he sostenido en Puente, 2011), y el propio Malpas cifra buena parte de su acusación en este carácter reduccionista de las categorías de espacio y lugar en la geografía crítica. El mismo Harvey ha definido su obra como una «teoría de lo concreto y lo particular en el marco de las determinaciones abstractas y universales de la teoría de la acumulación del capital de Marx» (Harvey, 1985: 144), algo que, teniendo en cuenta la más que espinosa cuestión del «fetichismo espacial» dentro del ámbito del marxismo ortodoxo, no es poco, en tanto que intento de dejar establecido el papel activo y generativo que tiene el espacio en el mantenimiento, la transformación y la difusión de los procesos históricos de acumulación del capital. Las criticas de Stuart Elden a que esto sea todo lo que haya que decir o hacer a la hora de construir una historia del territorio (y esto vale igualmente para la obra de Lefebvre; cfr. Brenner y Elden, 2009, y Elden, 2010) son, en este sentido, paralelas a las de Malpas, acerca de que todo lo que haya que decir sobre el lugar sea lo que puede decirse acerca de los procesos que lo constituyen.

29. Price (1994), por ejemplo, insiste en una versión posestructuralista de la aseveración harveysiana de que no hay nada que decir más allá del estudio de los procesos que construyen los lugares, las naturalezas y los espacios, es decir, de sus materializaciones concretas (y de 
tado de la confusa importación y, a menudo, indiscriminada aplicación en la disciplina de diferentes postulados (con un grado diferente de radicalidad en su constructivismo) de las epistemologías críticas acuñadas por los estudios contemporáneos en filosofía de la ciencia ${ }^{30}$. Si bien, en su práctica particular a través de investigaciones históricas concretas (sobre todo en los estudios contemporáneos en historia y filosofía de la ciencia), dichas perspectivas epistemológicas se han revelado efectivamente como muy interesantes ${ }^{31}$, no lo han sido tanto en la progresiva decantación que han ido teniendo en argumentos generales, donde el constructivismo que se predicaba en origen sobre cuestiones epistemológicas y se concretaba en el estudio de la producción y la legitimación del conocimiento, ha ido derivando difusamente hacia un constructivismo predicado en el plano ontológico ${ }^{32}$.

En un famoso y muchas veces comentado pasaje de la obra del filósofo Ian Hacking The Social Construction of What? (1999), el autor ofrecía una larga retahíla de los muy distintos tipos de cosas de las que, a lo largo de las últimas décadas, se ha predicado su «construcción social» (se trataba de una muestra extraída a partir de los títulos de libros de un catálogo de biblioteca). En dicha lista, aparecían citados elementos tan diversos como la «autoría», los "hechos», el «género», los «quarks», el «nacionalismo zulú», las «mujeres refugiadas» o el propio «conocimiento». No sin ironía, Hacking venía a poner de relieve que, debido al fervor crítico y al entusiasmo emancipador que, efectivamente, habían acompañado a estos debates, y con los que habían sido recibidas

la conexión de esos procesos a través de escalas globales debido a la propia naturaleza del sistema capitalista), o que poco interesa más allá del análisis de los lugares en los marcos económicos y discursivos donde se generan las determinaciones que son causa de la particular forma de darse estos lugares.

30. Cfr. Demeritt (2002) para un intento de tipología de los distintos modos de constructivismo, y sus fuentes filosóficas, en la geografía crítica anglosajona.

31. Este juicio podría aplicarse, sobre todo, a la denominada «sociología del conocimiento científico», que vendría a agrupar al llamado «programa fuerte» de Edimburgo (con autores como David Bloor o Steven Shapin, que, desde finales de los años setenta, fueron articulando una crítica sociológica a la ciencia desde presupuestos constructivistas), a la Escuela de Bath con su programa relativista (aplicado al estudio de la construcción social de la tecnología por autores como Harry Collins, Andrew Pickering o Trevor Pinch), y a los conocidos como «estudios de laboratorio» (con los más destacados trabajos del francés Bruno Latour con Steve Woolgar, que han servido para difundir este tipo de enfoques «micro» o etnometodológico, centrados en los pormenores de la actividad científica en sus contextos de producción). No obstante, podría también hacerse extensible, con excepciones, a los estudios culturales de la ciencia, denominación que agrupa, de forma igualmente laxa, distintas investigaciones interdisciplinarias sobre la ciencia, opuestas a los modos internistas de explicación de la misma. Véase Fuller (1993) o Hansen (2010) para una síntesis muy clara acerca de los distintos grupos a los que nos referimos. Véase también Segerstrale (2000: 1-40) para una división en dos grandes grupos en base a los términos en que cada uno de ellos sostiene las tesis constructivistas, pues dicho análisis es válido para lo que ha sucedido en la geografía anglosajona.

32. Cfr. Boghossian (2006: 178) sobre cómo, a pesar de la utilidad evidente del constructivismo social denunciando «la contingencia de aquellas de nuestras prácticas sociales que erróneamente habíamos llegado a considerar impuestas por la naturaleza, [...] perdió su rumbo cada vez que se empeñó en convertirse en una teoría general sobre la verdad y el conocimiento». 
inicialmente las aportaciones constructivistas, se fue generando, sin embargo, cierto clima de confusión entre las diferentes nociones de "construcción social» que llegaron a mezclarse en dichos debates, hasta el punto de no poder saberse muy bien, al cabo, de qué se estaba exactamente predicando la construcción social y, sobre todo, en qué términos se hacía (epistemológicos, ontológicos, políticos, etc.). Algo no baladí, pues de ello dependían en buena medida las consecuencias que, de dichos enfoques, habían de extraerse.

Éste ha sido claramente el caso de la utilización del constructivismo social respecto de los objetos geográficos, que si bien había resultado de gran relevancia e interés para el estudio de la producción del conocimiento geográfico (cfr. Puente, 2013), ha ido generando, sin embargo, una serie de malentendidos respecto de las posibilidades y las formas de teorización geográfica, que tienen mucho que ver con el estado de confusión conceptual del pensamiento geográfico contemporáneo al que aludía al inicio de este artículo.

Abordada la cuestión desde un punto de vista filosófico general, como hace Hacking (1999) al proporcionar una interpretación global y unificadora de este fenómeno contemporáneo, las tesis constructivistas, básicamente, habrían venido a sostener la idea de que las cosas no tienen necesariamente que ser como han sido, o presentarse bajo la manera en que se dan actualmente, porque esa forma de existir no es en absoluto inevitable, ni define en manera alguna algo que pueda calificarse como la «naturaleza» dada o la «esencia» de tales cosas. Lo relevante para la cuestión es que, a esta tesis central, suelen sumársele o derivársele frecuentemente otras dos más radicales: a saber, la de que, al señalar el carácter construido de las cosas (cosas, sobre todo, como el conocimiento científico), en realidad, lo que se suele denunciar es que tal forma de darse esa cosa es mala o censurable, y que, por tanto, sería conveniente, o bien transformarla radicalmente, o bien eliminar tal estado de cosas. Por supuesto, para que esta argumentación funcione, la precondición del constructivismo ha de ser la siguiente: «En el presente estado de cosas, $X$ se toma por dado; $X$ aparece como inevitable» (Hacking, 1999: 12), para, a continuación, poder demostrar que forma parte de la realidad social, y es por ella producida (pertenece, por tanto, al mundo de los "hechos» y no al de lo «dado»), con lo cual desenmascara la falsedad de las explicaciones acerca de dichos fenómenos disponibles hasta el momento.

Estos son los tres tipos de tesis que, combinadas de distinta manera y aplicadas poniendo un énfasis diferente en una u otra de ellas, Hacking identificó como el núcleo central de los enfoques constructivistas. Siendo sólo la primera de esas tres tesis la premisa básica del constructivismo, «la mayoría de la gente que usa la idea de la construcción social quiere entusiastamente criticar, cambiar o destruir ese $X$ [el objeto del que se predica su carácter de constructo cultural o social] que no le gusta en el orden establecido de las cosas» (Hacking, 1999: 7). Una vez que prácticamente cualquier objeto de estudio pensable ha pasado a erigirse como candidato propicio a ser sometido a todo tipo de maniobras epistemológicas que, al cabo, lo desposeen de su pretendida apariencia de necesidad (y, de paso, de cualquier valor que pudiera habérsele otorgado a dicho objeto en tiempos sin duda más oscuros y proclives a la ceguera que los actuales), la estrategia desen- 
mascaradora acaba adquiriendo una circularidad que suele dar al traste con lo que pudiera haber tenido de valioso en algún momento ${ }^{33}$.

A pesar de la diversidad de maneras y modos en que este tipo de razonamiento se ha aplicado en la geografía contemporánea ${ }^{34}$, resulta fácil reconocer las referidas premisas señaladas por Hacking en la literatura sobre la producción social de la naturaleza, del espacio o del lugar, así como el potencial de transformación que estas reconfiguraciones discursivas asumen, como forma de responder a las determinaciones sociales, culturales y económicas a las que ellas mismas están sometidas y que las producen ${ }^{35}$. Acaso sea en lo tocante a la categoría de lugar donde más claramente se muestran los efectos de este tipo de análisis constructivistas, ya que la insistencia en el carácter contingente de los lugares, no sólo ha llevado a negar la validez de cualquier otro plano de análisis que no dé cuenta de esa pura contingencia, sino que ha sido la clave para reforzar y encapsular la equívoca inferencia (hecha lugar común en el pensamiento geográfico actual) que se hace entre, por un lado, los efectos negativos generados por determinado tipo histórico de discursos sobre el lugar y las políticas de lugar asociados a ellos y, por otro lado, la categoría misma de lugar, a la que se le atribuyen dichos efectos (que ya no son consecuencias de políticas y lugares concretos, sino efectos deletéreos intrínsecos al hecho mismo de defender la importancia del lugar).

La particular manera en que estas dos formas de argumentación que antes señalábamos (la sospecha sobre el lugar y el esquema constructivista) convergen ha sido sintetizada por Malpas así:

La relevancia [y la clave de su éxito, podría añadirse] de la interpretación constructivista del lugar subyacente en todos estos casos no reside únicamente en la

33. Véase Valdecantos (2008: 26-30) para una mordaz y agudísima crítica acerca del «furor constructivo» en las humanidades y en las ciencias sociales contemporáneas, así como el predicamento del que ha gozado esta doctrina hasta haberse convertido en una de las «formas canónicas de comprender el mundo contemporáneo» (ibídem: 30). Valdecantos ha afirmado, no sin ironía y con acierto, que «la cosmodicea construccionista resulta inmejorable como ideología para la clase media» (ibídem: 28): la rápida difusión que han tenido estos enfoques en medio del malestar cultural contemporáneo y su entusiasta acogida se explican, en parte, por cómo proporcionan una estrategia desenmascaradora al alcance de todos, que generaliza una tesis más o menos simplificada del constructivismo, fácilmente aplicable a los distintos niveles de nuestra experiencia contemporánea.

34. En Jones (2002) puede encontrarse un análisis sobre las distintas formas de constructivismo en la investigación geográfica. También lo vemos en Demeritt (1998, 2001, 2002).

35. Lo interesante, para el caso, de la formalización que hace Hacking del argumento constructivista es que puede comprobarse hasta qué punto este tipo de razonamiento ha devenido un lugar común en buena parte del pensamiento contemporáneo, también el geográfico, pues resulta fácil detectar cómo estas premisas operan en muchos geógrafos críticos que ni siquiera sostienen un compromiso explícito con el constructivismo, como es el caso de buena parte de la geografía cultural anglosajona. Al hecho de que tal geografía se dedique, sin más pretensiones teóricas, al análisis de la construcción discursiva, cultural o socioeconómica (la lista adjetivadora aquí suele, de común, prolongarse indefinidamente, aunque sea de manera algo previsible) de tal o cual lugar no parece en absoluto cosa reprobable, ni a la que haya de objetarse algo serio, pues, al cabo, se trata de una actividad no especialmente novedosa entre quienes tienen por costumbre ocuparse de asuntos cargados de historia y cultura. 
manera en que conecta con la idea de contingencia del lugar, sino también por la forma en que proporciona un medio para comprender la efectividad política y ética del lugar. Puede que el lugar sea contingente, pero, aún así, tiene efectos; y el argumento en contra del lugar consiste específicamente en que tiene efectos ética y políticamente deletéreos. Dichos efectos no pueden derivarse del carácter del lugar en tanto que estructura ontológica necesaria, sino que deben derivarse de la forma en que el lugar opera dentro de una estructura de pensamiento, lenguaje y socialidad determinada. Interpretar el lugar como algo ya construido social o discursivamente, como él mismo determinado por factores sociales y discursivos, significa situar previamente el lugar dentro de un marco de efectos retóricos, discursivos y sociales — significa, podría decirse, posicionarlo ya precisamente de tal forma que inmediatamente tiene un potencial ético o político, sea positivo o negativo, y, por lo tanto, hacerlo aparecer como algo que es susceptible de evaluación ética o política- Es precisamente porque podemos, tanto comprender el carácter del lugar como algo que produce efectos, como, asimismo, captar el carácter contingente de esos efectos en tanto que consecuencia de haber entendido el carácter contingente del lugar, por lo que el argumento contra el lugar puede tener el impacto que, de hecho, tiene [esto es, porque hace creer que la solución está en teorizar de otra forma ese concepto, amoldándolo al esquema de las respuestas políticas que necesitan los problemas particulares que presentan hoy en día los lugares concretos].

[Desde estos puntos de vista constructivistas] el lugar puede ser nocivo en sus efectos, pero esos efectos no son inevitables, y podemos eludirlos por medio de un cambio en las formaciones discursivas dentro de las cuales estos operan o, más obviamente, reorientando el discurso alejándose de cualquier foco en la categoría del lugar [centrándose en el espacio, por ejemplo]. Tal cambio en el discurso, se argumenta, sería política y éticamente progresista en sus consecuencias. (Malpas, Ethos and Topos: s/f. Traducción propia).

Bajo esta óptica se entiende todo el esfuerzo que algunos geógrafos críticos han hecho para reemplazar la idea de lugar por otras más «abiertas» o «inclusivas», proponiendo teorizaciones alternativas que subrayan sólo, o sobre todo, los aspectos relacionales del lugar ${ }^{36}$, dando por sentado que esto impide que se generen los efectos éticos y políticos que Malpas comenta que suelen atribuirse a otras formas más tradicionales de entender el lugar. Hay, por tanto, una ambigüedad esencial en cómo se maneja la idea de contingencia en todo este tratamiento constructivista del lugar, y que es la que atañe a la diferencia existente entre, por una parte, el modo contingente de darse los lugares en sus instanciaciones particulares a lo largo de la historia y a través del espacio, así como de aquello con respecto a lo que se predica la contingencia misma en este tipo de análisis (los lugares tout court). Que el «lugar» sea entendido no como una estructura ontológica, sino exclusiva y meramente como una cate-

36. Como en Massey (2005), y ahí es donde radica la diferencia entre el sentido de relacionalidad que Malpas también le da al lugar, pero que siempre está conectada con la idea de limitación (boundl limit), algo a lo que Massey no atiende debidamente y que tiene que ver, en parte, con su frecuente indistinción de las categorías de espacio y lugar. Véase, sobre todo, Malpas (2012c) para esta crítica. 
goría discursiva, dependiente por entero de las formaciones discursivas (y sus propias determinaciones sociohistóricas) en que se inserta, tal es el caso de los geógrafos referidos, tiene como corolario la errónea asunción del carácter igualmente contingente de todo aquello, sin discriminación alguna, que es objeto de tales construcciones discursivas ${ }^{37}$. Por supuesto, el asunto dista mucho de poder identificarse con esta meridiana claridad, pues, con gran frecuencia, la mencionada ambigüedad respecto de la contingencia, que tiende a enredar los tratamientos constructivistas del lugar y cuajarlos de más de una vacilación y oscuridad argumentativa (lo cual, desde luego, no hace sino empeorar la indistinción que, de ordinario, suelen sufrir los propios términos de espacio y lugar en estos mismos trabajos) acostumbra, además, a presentarse aderezada de algún que otro elemento de necesidad, con lo cual se refuerza el sólido mecanismo inferencial que configura la maquinaria constructivista (pues dicha necesidad no puede sino predicarse de la propia forma discursiva de darse los lugares).

Con toda seguridad, los lugares, como los cuerpos, son elementos sometidos y sometibles a múltiples procesos que los configuran cultural, histórica, social o semióticamente, y como tales han de analizarse, pero no es menos cierto que ambos son estructuras ineludibles de la experiencia humana, y parece una apuesta no del todo segura pretender que puede prescindirse de tales categorías sin más.

\section{Conclusiones. Pensamiento topográfico y pensamiento geográfico}

Al cabo, por supuesto, ésta sería una discusión más bien fútil (o, peor, sospechosamente propia de filósofos aguafiestas, dados siempre a este tipo de pesadísimos e irrelevantes matices y no menos severísimas puntualizaciones), si no fuera porque a lo que afecta de lleno esta ambigüedad sobre aquello de lo que se predica y se asume la contingencia es a la naturaleza del cambio que se da por sentado producirán las formas alternativas de teorizar el lugar, asunto éste central en los proyectos de la geografía crítica, como es lógico. No en vano, la denuncia de Malpas pone precisamente el acento en el hecho de que unas formas de tratamiento del lugar como las que él defiende con su propuesta de "pensamiento topográfico» deberían, en el fondo, permitirnos adoptar una postura mucho más crítica con el capitalismo contemporáneo y con los sistemas tecnológicos y burocráticos asociados a éste, que la que proporcionan las argumentaciones constructivistas de las que se valen los geógrafos referidos. Lo que Malpas pone en evidencia (al modo conocido del cuento de El traje nuevo del emperador) es que los vocabularios teóricos y las retóricas espaciales

37. Parece ocioso reparar en la caída en formas de antirrealismo que rayan a menudo lo cómico, cuando no lo grotesco, que esto supone, aunque es algo que Malpas hace explícito en su crítica, al subrayar las variadas formas en que el constructivismo suele acompañarse de formas no menos variadas de subjetivismo o idealismo (véase su texto en este mismo número, sobre todo, las páginas 14 y s.). 
de moda, tan triunfalmente plagadas de redes, relaciones, fluideces y aperturas, en el fondo, no hacen sino reproducir (paradójicamente en nombre de los más estimables fines y valores críticos, y con la mente siempre puesta en las alturas de la teoría) el mismo tipo de marco conceptual que posibilita la progresiva expansión del capitalismo a todos los ámbitos de la vida.

No es en absoluto descartable que, a estas alturas, y después de todos los exabruptos proferidos, ninguno de los argumentos aquí presentados resulte lo suficientemente convincente como para que empecemos, cuando menos, a precavernos de la palabra teorizar puesta en boca del geógrafo ardorosa o distraídamente constructivista, y, por consiguiente, de entrecomillar su uso del término crítico, cuando éste tiene a bien adjetivar así a la propia tarea teórico-geográfica (y de corriente lo hará, además, en revistas que obtienen del aparato tecnocrático que lo evalúa el mejor de los aplausos, y que engrosan la cuenta de resultados de un grupo editorial sostenido por el sistema económico que éste no para de denostar, como no podía ser de otra forma). Precaverse y entrecomillar son sendas operaciones necesarias a fin de parar mientes en la conveniencia de cuestionar si aquello que así se refiere merece semejante calificación o si, por el contrario, haríamos mejor en buscar formas alternativas de elaborar todos estos asuntos ${ }^{38}$.

Aun cuando nada de lo expuesto aquí resulte persuasivo, estoy segura de que la propuesta de "pensamiento topográfico» de Malpas sabrá despertar algunos interrogantes y no pocas inquietudes respecto a qué caminos transitar para poder articular una estructura de comprensión (en la que «lugar» y «espacio» estén implicados) más crítica y resistente con el orden sociopolítico contemporáneo, capaz, por tanto, de captar la esencia moderna de algunos procesos que, en realidad, ni la globalización bajo su forma actual, ni el posmodernismo como supuesto paradigma rompedor o superador de esos rasgos, han conseguido desactivar.

Cuál sea la relación que tal "pensamiento topográfico" mantenga con el pensamiento geográfico (pues no resultaría lícito ni coherente, después de todo lo argumentado, zanjar la cuestión abogando por una mera subsunción del segundo en el primero) es asunto no del todo fácil de dirimir, al menos una vez que se hacen claras las consecuencias de que la geografía se haya instalado, con la voluntad y el ahínco que ha demostrado, en cierto proyecto que la hace dependiente (aunque ésta haya sido abrazada como la más liberadora de las sujeciones voluntarias) de una serie de marcos teóricos y epistemológicos que la abocan a una situación paradójica. A lo largo de estas páginas, he tratado de señalar algunas de esas paradojas, con el fin de enmarcar el sentido y el valor que creo puede tener la aportación de Malpas.

Cabe añadir, por último, que una elaboración filosófica de los conceptos geográficos como la que el enfoque topológico que Malpas defiende (y es conveniente aquí subrayar lo de "enfoque», para no caer de nuevo en la trampa de tomar por «teoría espacial» lo que no es, ni pretende serlo), no tendría por

38. Para unas reflexiones provechosas sobre el entrecomillamiento, véase Valdecantos (2007: 234-241, y 2014: 21-33). 
qué venir a estorbar el común desempeño de los quehaceres del geógrafo, por lo que no está de más tomarse con cierta reserva las propias admoniciones de Malpas a los geógrafos al final de su texto «Pensar topográficamente», y bien merecidamente éstas serán objeto de desdén por parte de quien nunca se dejó engatusar por los cantos de sirena de la teoría geográfica.

Queda dicho, no obstante, que, si de "teoría geográfica» se trata, y Malpas ha entrado de lleno al juego, no está claro por qué los geógrafos hubieran de andarse con medias tintas, y bien está, por tanto, que prueben algo de lo que han creído debía ser su propia medicina, aunque esto no suponga sino profundizar aviesamente en la paradoja en que andan metidos.

\section{Agradecimientos}

Agradezco al Consejo Editorial de la revista el haber aceptado mi propuesta de invitar a Jeff Malpas a realizar una contribución a este número, además de haberme permitido glosar y comentar algunos aspectos de su obra en este texto. En especial, agradezco a Miguel Solana su ayuda y su paciencia a lo largo de todo el proceso de gestación y edición de sendos artículos.

\section{Referencias bibliográficas}

AgNew, John (2003). «Contemporary political geography: Intellectual heterodoxy and its dilemmas». Political Geography [en línea], 22, 603-606. $<$ http://dx.doi.org/10.1016/S0962-6298(03)00063-5>

Barnett, Clive (2006). «Temporality and the paradoxes of democracy». Political Geography [en línea], 24 (5), 641-647. <http://dx.doi.org/10.1016/j.polgeo.2005.01.011>

- (2008a). «Political Affects in Public Space: Normative Blind-Spots in Nonrepresentational Ontologies». Transactions of the Institute of British Geographers [en línea], 33 (2), 186-200. <http://dx.doi.org/10.1111/j.1475-5661.2008.00298.x>

- (2008b). "Theorising democracy geographically». Geoforum [en línea], 39 (5), 1637-1640.

<http://dx.doi.org/10.1016/j.geoforum.2008.07.001>

- (2010). «Geography and ethics: Justice unbound». Progress in Human Geography, 35 (2), 246-255.

- (2012). «Situating the geographies of injustice in democratic theory». Geoforum [en línea], 43 (4), 677-686. <http://dx.doi.org/10.1016/j.geoforum.2011.03.002>

BarnetT, Clive y Low, Murray (2004). «Geography and Democracy: An Introduction». En: BarnetT, Clive y Low, Murray (eds.). Spaces of Democracy: Geographical Perspectives on Citizenship, Participation and Representation [en línea]. Londres: SAGE, 1-22. $<$ http://dx.doi.org/10.4135/9781446216309.n1>

Beistegui, Miguel (2011). «The Place of Place in Heidegger's Topology». International Journal of Philosophical Studies [en línea], 19 (2), 277-283. $<$ http://dx.doi.org/10.1080/09672559.2011.560476> 
Boghossian, Paul (2006). El miedo al conocimiento: Contra el relativismo y el constructivismo. Madrid: Alianza, 2009.

Brenner, Neil y Elden, Stuart (2009). "Henri Lefebvre on State, Space, Territory». International Political Sociology [en línea], 3 (4), 353-377. <http://dx.doi.org/10.1111/j.1749-5687.2009.00081.x>

CAmeron, John (2004). «Some Implications of Malpas' Place and Experience for Place Ethics and Education». Environmental \& Architectural Phenomenology Newsletter [en línea]. <http://www.arch.ksu.edu/seamon/cameron_malpas.htm>

CAPEL, Horacio (1981). Filosofía y ciencia en la geografía contemporánea: Una introducción a la geografía. Barcelona: Ediciones del Serbal.

- (1987). Geografía humana y ciencias sociales: Una perspectiva histórica. Barcelona: Montesinos.

Casey, Edward (1993). Getting Back to Place. Toward a Renewed Understanding of the Place-World. Bloomington: Indiana University Press.

- (1997). The Fate of Place. A Philosophical History. Berkeley \& Los Angeles: University of California Press.

- (2001). «J. E. Malpas' Place and Experience: A Philosophical Topography (Cambridge University Press, 1999) Converging and diverging in/on place» [en línea]. Philosophy \& Geography, 4 (2), 225-230. <http://dx.doi.org/10.1080/10903770123141>

Collinge, Chris (2006). «Flat ontology and the deconstruction of scale: A response to Marston, Jones and Woodward». Transactions of the Institute of British Geographers [en línea], 31, 244-251. <http://dx.doi.org/10.1111/j.1475-5661.2006.00201.x>

Corbridge, Stuart (1998). «Reading David Harvey: entries, voices, loyalties». Antipode [en línea], 30 (1), 43-55.

<http://dx.doi.org/10.1111/1467-8330.00066>

Crowell, Steven (2011). «Is transcendental topology phenomenological?». International Journal of Philosophical Studies [en línea], 19 (2), 267-276. <http://dx.doi.org/10.1080/09672559.2011.560480>

Dardel, Eric (1951). L'homme et la terre. París: Collin (Traducción al castellano de Maria Beneyto, El hombre y la tierra. Naturaleza de la realidad geográfica. Madrid: Biblioteca Nueva, 2013).

Demeritt, David (1998). "Science and Social Constructivism». En: Braun, Bruce y Castree, Noel (eds.). Remaking Reality. Londres: Routledge, 173-192.

- (2001). «Being Constructive about Nature». En: Castree, Noel y Braun, Bruce (eds.). Social Nature: Theory, Practice and Politics. Oxford: Blackwell, 22-40.

- (2002). "What is the "social construction of nature"?: A typology and a sympathetic critique». Progress in Human Geography [en línea], 26 (6), 767-790. <http://dx.doi.org/10.1191/0309132502ph402oa>

Delgado Macheca, Ovidio (2003). Debates sobre el espacio en geografía contemporánea. Bogotá: Universidad Nacional de Colombia.

Doel, Marcus (1999). Poststructuralist Geographies: The Diabolical Art of Spatial Science. Edimburgo: Edinburgh University Press.

Elden, Stuart (2001a). Mapping the Present: Heidegger, Foucault and the Project of a Spatial History. Londres y Nueva York: Continuum.

- (2001b). «Politics, Philosophy, Geography: Henri Lefebvre in Recent Anglo-American Scholarship». Antipode [en línea], 33 (5), 809-825.

<http://dx.doi.org/10.1111/1467-8330.00218> 
- (2003). «The importance of History: A reply to Malpas». Philosophy and Geography [en línea], 6 (2), 219-224.

<http://dx.doi.org/10.1080/1090377032000114660>

- (2009). «Reassessing Kant's geography». Journal of Historical Geography [en línea], 35 (1), 3-25.

<http://dx.doi.org/10.1016/j.jhg.2008.06.001>

- (2010). «Thinking territory historically». Geopolitics [en línea], 15 (4), 757-761. <http://dx.doi.org/10.1080/14650041003717517>

- (2013). "Leibniz and geography: Geologist, aleontologist, biologist, historian, political theorist and geopolitician». Geographica Helvetica [en línea], 68, 81-93. <http://dx.doi.org/10.5194/gh-68-81-2013>

Fuller, Steve (1993). Philosophy of Science and its Discontents. 2a ed. [en línea]. Londres y Nueva York: Guilford Press. <http://dx.doi.org/10.1086/289740>, <http://dx.doi.org/10.1086/289724>

García Ramón, Maria Dolors (1985). Teoría y Método en Geografía Humana Anglosajona. Barcelona: Ariel.

Gregory, Derek (1994). Geographical Imaginations. Oxford: Blackwell.

Hacking, Ian (1999). The Social Construction of What? Cambridge: Harvard University Press. Traducción al castellano de Jesús Sánchez Navarro: ¿La construcción social de qué? Barcelona: Paidós Ibérica, 2001.

Hansen, Allan Dreyer (2010). «Dangerous Dogs, Constructivism and Normativity: The Implications of Radical Constructivism». Distinktion: Scandinavian Journal of Social Theory [en línea], 11 (1), 93-107. <http://dx.doi.org/10.1080/1600910X.2010.9672758>

Harvey, David (1985). "The Geopolitics of Capitalism». En: Gregory, Dereck y UrRY, John (eds.). Social Relations and Spatial Structures. Londres: Macmillan, 128-63.

- (1993). «From Space to Place and Back Again: Reflections on the Condition of Postmodernity». En: Bird, J.; Curtis, B.; Putnam, T.; Robertson, G. y Tickner, L. (eds). Mapping the Futures: Local Cultures, Global Change. Londres: Routledge, 3-29.

- (1996). Justice, Nature and the Geography of Difference. Maden y Oxford: Blackwell.

JoNES, S. (2002). "Social constructionism and the environment: through the quagmire». Global Environmental Change [en línea], 12, 247-251. <http://dx.doi.org/10.1016/S0959-3780(02)00062-6>

Kolb, David (2008). Sprawling Places. Athens: The University of Georgia Press.

Ley, David y Samuels, Marwyn (1978). Humanistic Geographies: Prospects and Problems. Londres: Croom Helm.

Lindón, Alicia y Hiernaux, Daniel (2007). Tratado de Geografía Humana. Barcelona: Anthropos.

- (2011). Los giros de la geografía humana: Desafíos y horizontes. Barcelona: Anthropos.

Lorimer, Hayden (2005). «Cultural geography: The busyness of being "more-thanrepresentational”". Progress in Human Geography [en línea], 29 (1), 83-94. <http://dx.doi.org/10.1191/0309132505ph531pr>

Malpas, Jeff (1992). Donald Davidson and the Mirror of Meaning. Cambridge: Cambridge University Press.

- (1999a). Place and Experience: A Philosophical Topography. Cambridge: Cambridge University Press. 
- (1999b). «Finding Place: Spatiality, Locality, and Subjectivity». En: Light, Andrew y Sмiтh, John (eds.). Philosophies of Place: Philosophy and Geography III. Lanham: Rowman and Littlefield.

- (1999c). "The constitution of the mind: Kant and Davidson on the unity of consciousness». International Journal of Philosophical Studies [en línea], 7, 1-30. <http://dx.doi.org/10.1080/096725599341947>

- (1999d). «Locating Interpretation: The Topography of Understanding in Heidegger and Davidson». Philosophical Topics [en línea] 27, 129-148. <http://dx.doi.org/10.5840/philtopics19992727>

- (2001a). "Comparing Topographies: Across Paths/Around Place: A Reply to Casey». Philosophy \& Geography [en línea], 4 (2), 231-238. <http://dx.doi.org/10.1080/10903770123850>

- (2001b). «Governing Theory: Ontology, Methodology and the Critique of Metaphysics». En: Wiскнам, Gary y Pavlich, George (eds.). Rethinking Law, Society and Governance: Foucault's Bequest. Oxford: Hart Publishing, $125-140$.

- (2002). "The weave of meaning: holism and contextuality». Language and Communication, 22, 403-419.

- (2003a). «Bio-medical Topoi-the dominance of space, the recalcitrance of place, and the making of persons». Social Science and Medicine [en línea], 56 (11), 2343-2351.

<http://dx.doi.org/10.1016/S0277-9536(02)00233-2>

- (2003b). "On the map: comments to Stuart Elden's Mapping the Present: Heidegger, Foucault and the Project of a Spatial History». Philosophy \& Geography [en línea], 6 (2), 213-18.

<http://dx.doi.org/10.1080/1090377032000114651>

- (2004a). «Place and Topography: Responding to Cameron and Stefanovic». Environmental and Architectural Phenomenology, 15 (3), 8-10.

- (2004b). «Holism, realism and truth: How to be an anti-relativist and not give up on Heidegger (or Davidson) - a debate with Christopher Norris». International Journal of Philosophical Studies [en línea], 12, 339-56. <http://dx.doi.org/10.1080/0967255042000243984>

- (2006). Heidegger's Topology: Being, Place, World. Cambridge: MIT Press.

- (2007). Transcendental Heidegger. Coeditado con Steven Galt Crowell. Stanford: University Press.

- (2008). «Heidegger, Geography, and Politics». Journal of the Philosophy of History [en línea], 2, 185-213. <http://dx.doi.org/10.1163/187226308X315031>

- (2010a). "Truth, Narrative, and the Materiality of Memory: An Externalist Approach in the Philosophy of History». Journal of the Philosophy of History [en línea], 4, 328-353.

<http://dx.doi.org/10.1163/187226310X536204>

- (2010b). Consequences of Hermeneutics. Coeditado con Santiago Zabala. Chicago: Northwestern University Press.

- (2011a). The Place of Landscape: Concepts, Contexts, Studies. Cambridge: MIT Press.

- (2011b). «Philosophy, topography and triangulation». En: Amoretti, Cristina y Preyer, Gerhard (eds.). Triangulation. Frankfurt: Ontos, 257-259.

- (2012a). Heidegger and the Thinking of Place. Cambridge: MIT Press. 
- (2012b). «Is there an ethics of place?». Localities, 2, 7-31.

- (2012c). «Putting Space in Place: Relational Geography and Philosophical Topography». Planning and Environment D: Space and Society, 30, 226-242.

- (2012d). "Building Memory». Interstices. Journal of Architecture and Related Arts, $13,11-21$.

- (2014). Routledge Companion to Philosophical Hermeneutics. Coeditado con HansHelmuth Gander. Londres: Routledge.

- (2015). «Pensar topográficamente: Lugar, espacio y geografía». Documents d'Anàlisi Geogràfica, 61 (2), 199-229.

- (s/f). The Remembrance of Place [en línea]. <http://jeffmalpas.com/downloadable-essays/>

- (s/f). Ethos and Topos: On the Ethics and Politics of Place. Manuscrito.

Malpas, Jeff y Miller, Linn (2009). «Home and the Place of Memory». Haccaeity Papers, 4, 29-47.

Massey, Doreen (1993a). «Power-geometry and a progressive sense of place». En: Bird, J.; Curtis, B.; Putnam, T.; Robertson, G. y Tickner, L. (eds.). Mapping the Futures: Local Cultures, Global Change. Londres: Routledge, 59-69.

- (1993b). «Politics and Space/Time». En: Keith, Mike y Pile, Steve (eds.). Place and the politics of identity. Londres y Nueva York: Routledge, 141-161.

- (1994). Space, Place and Gender. Cambridge: Polity Press.

- (1995). "The conceptualization of place». En: Massey, D. y Jess, P. A place in the World? Oxford: Oxford University Press, 45-85.

- (2004). "Geographies of responsibility». Geografiska Annaler: Series B, Human Geography [en línea], 86 (1), 5-18.

<http://dx.doi.org/10.1111/j.0435-3684.2004.00150.x>

- (2005). For Space. Londres: Sage.

NeL·Lo, Oriol (2012). Franceso Indovina: Del análisis del territorio al gobierno de la ciudad. Barcelona: Icaria.

Olson, Elizabeth y SAYer, Andrew (2009). «Radical Geography and its Critical Standpoints: Embracing the Normative». Antipode, 41 (1), 180-198. <http://dx.doi.org/10.1111/j.1467-8330.2008.00661.x>

Ortega Cantero, Nicolás (1987). Geografía y cultura. Madrid: Alianza.

Ortega Valcárcel, José (2002). Los horizontes de la Geografía: Teoría de la Geografía. Ariel: Barcelona.

Price, Patricia (1994). Dry Places: Landscapes of Belonging and Exclusion. Minneapolis: Minnesota University Press.

Puente, Paloma (2009). «Viajes por los paisajes urbanos posmodernos: O de cómo ubicarse en medio del caos». Boletín de la Asociación de Geógrafos Españoles, 51, 275-304.

- (2011). «La reconstrucción de los enfoques críticos contemporáneos y el rol del espacio: Una visión desde la geografía». Documents d'Anàlisi Geogràfica, 57 (2), 223-254.

- (2013). «Los desplazamientos críticos de la historia de la geografía: Las diversas formas de reflexividad en los debates historiográficos de la disciplina». Terra Brasilis (Nova Série), 2, s/p.

Relph, Edward (1976). Place and Placelessness. Londres: Pion.

- (2008). «Disclosing the Ontological Depth of Place: Heidegger's Topology by Jeff Malpas». Environmental \& Architectural Phenomenology Newsletter [en línea]. <http://www.arch.ksu.edu/seamon/Relph_Malpasreview08.htm>

Sack, Robert (1997). Homo Geographicus: A Framework for Action, Awareness, and Moral Concern. Baltimore: The Johns Hopkins University Press. 
SAYER, Andrew (2000). Realism and Social Science [en línea]. Londres: SAGE. <http://dx.doi.org/10.4135/9781446218730>

Segerstrale, Ullica (2000). Beyond the science wars: The missing discourse about science and society. Nueva York: SUNY Press.

Staddon, Chad (2009). «Review on Martin Heidegger: Theorist of Space. By Theodore R. Schatzki». Tijdschrift voor Economische en Sociale Geografie [en línea], 100 (3), 371-373.

<http://dx.doi.org/10.1111/j.1467-9663.2009.543_4.x>

STEFANOvic, Ingrid (2004). «Speaking of Place: In Dialogue with Malpas». Environmental \& Architectural Phenomenology Newsletter [en línea]. <http://www.arch.ksu. edu/seamon/stefanovic_malpas.htm>

Thrift, Nigel (2008). Non-Representational Theory: Space, Politics, Affect. Nueva York: Routledge.

Tuan, Yi-Fu (1974) Topophilia. A Study of Environmental Perception, Attitudes and Values. Nueva York: Columbia University Press, ed. 1990. (Hay traducción al castellano de Flor Durán de Zapata, Topofilia. Un estudio sobre percepciones, actitudes y valores medioambientales. Melusina: Madrid, 2007).

- (1977). Space and Place: The Perspective of Experience. Minneapolis: University of Minnesota Press.

Valdecantos, Antonio (2007). La moral como anomalía. Barcelona: Herder.

- (2008). La fábrica del bien. Madrid: Síntesis.

- (2014). La excepción permanente: O la construcción totalitaria del tiempo. Madrid: Díaz \& Pons.

WyLy, Elvin (2009). «Strategic positivism». Professional Geographer [en línea], 61 (3), 310-322. <http://dx.doi.org/10.1080/00330120902931952>

Young, Julian (2011). "Heidegger's Heimat». International Journal of Philosophical Studies [en línea], 19 (2), 285-293.

<http://dx.doi.org/10.1080/09672559.2011.560478> 